\title{
Material properties of the cyanobacterial reserve
}

\section{polymer multi-L-arginyl-poly-L-aspartate}

\section{(cyanophycin)}

Nikita A. Khlystov ${ }^{\ddagger}$, Wui Yarn Chan ${ }^{\ddagger}$, Aditya M. Kunjapur, Weichao Shi, Kristala L. J. Prather and Bradley D. Olsen ${ }^{*}$.

Department of Chemical Engineering, Massachusetts Institute of Technology, 77 Massachusetts Ave, Cambridge MA, 02139

AUTHOR INFORMATION

Corresponding Author

*Email: bdolsen@mit.edu

\section{Author Contributions}

$\ddagger$ These authors contributed equally.

The manuscript was written through contributions of all authors. All authors have given approval to the final version of the manuscript. 
Bio-sourced macromolecules such as cyanophycin are an attractive source for alternative, sustainable plastics. While the chemical structure and biological function of cyanophycin have been previously investigated, its material properties remain largely unexplored. This study investigates the structural, thermal, mechanical, and solution properties of cyanophycin produced from recombinant Escherichia coli. Unplasticized, it has an elastic compression modulus of about $560 \mathrm{MPa}$ and undergoes brittle failure at $78 \mathrm{MPa}$. Cyanophycin exhibits thermal stability in air up to $200^{\circ} \mathrm{C}$ and does not undergo glass transition within its limit of thermal stability. The polypeptide is amorphous and has no long-range ordering in the solid state. In solution, watersoluble cyanophycin is thermoresponsive, exhibiting both upper and lower critical solution temperatures. Because the feasibility of industrial scale cyanophycin production through fermentation has been well studied, an expanded understanding of its materials properties should contribute to the development of new applications for this biopolymer.

KEYWORDS: Cyanophycin, sustainable polymer, non-ribosomal peptide, ionomer

\section{INTRODUCTION}

Society produces, consumes, and discards an extraordinary range and quantity of plastics[1]. Globally, around three hundred million metric tons of plastic are produced each year, sourced almost entirely from non-renewable petroleum-based chemicals[2]. The vast majority of plastic municipal solid waste is not recovered[3] and instead persists as environmental pollution, especially in marine habitats[4-6]. This has led to increased interest in the development and 
production of biodegradable plastics, notably poly(lactic acid) (PLA), poly(e-caprolactone) (PCL), and poly( $\beta$-hydroxyalkanoates) (PHA), among others [7, 8].

Biologically-derived macromolecules present a potentially sustainable and environmentally compatible feedstock for material synthesis. Microorganisms are able to efficiently catabolize biological polymers under appropriate conditions, reducing their persistence and impact on the environment $[9,10]$. Polymers in the form of biomass are abundant and are replenished more quickly than petroleum sources[11, 12]. Biomass and microbial systems have already been successfully harnessed as alternatives to petroleum in the production of fuels and chemicals, and parallel efforts can adequately address sustainability and environmental concerns in polymer materials as well[11, 13-16]. Several examples of bio-sourced polymers used as consumer plastics already exist today, and certain other high-production plastics can be feasibly replaced by those derived from biomass[11, 16, 17].

Cyanophycin, also known as multi-L-arginyl-poly-L-aspartate, is one biologically-derived polymer that has been investigated in efforts to understand its properties and synthesis in various organisms [18-23]. This polypeptide is native to most cyanobacteria, where it is employed as a temporary nitrogen reserve[24-26]. It is non-ribosomally synthesized by cyanophycin synthetase, which is encoded by the gene $c p h A$ and produces a polydisperse polypeptide of molecular mass between 25 and $100 \mathrm{kDa}$ as estimated by gel electrophoresis[25, 27]. Cyanophycin is efficiently degraded into its constituent dipeptides by cyanophycinase despite being resistant to a range of other proteases[10, 28]. The molecular structure of cyanophycin consists of a polyaspartate backbone with an arginine moiety attached via its $\alpha$-amino group to the $\beta$-carboxyl group of each aspartate. This structure produces a highly-charged, net-neutral polyzwitterion that readily selfassociates and requires strong ionic conditions to solubilize[29]. When expressed in transgenic 
microorganisms, cyanophycin has a lower molecular mass (25-35 kDa), and significant amounts of lysine replace arginine[27, 30]. The incorporation of lysine appears to disrupt self-association and thereby enhance solubility in pH-neutral aqueous conditions, resulting in a lysine-rich 'water-soluble' form of cyanophycin in addition to the arginine-rich 'water-insoluble' form[31, 32].

Development of commercial applications for cyanophycin has focused primarily on its chemical derivatives. For example, the $\beta$-arginine groups in cyanophycin can be selectively hydrolyzed to yield unbranched poly( $\alpha$-L-aspartic acid), which has numerous economicallyimportant applications as a replacement for non-biodegradable polyacrylates[10, 33-35]. Cyanophycin can also be hydrolyzed into its constituent dipeptides and amino acids for use in nutrition and health[36]. In light of these applications, industrial-scale production of cyanophycin has been successfully demonstrated in a range of recombinant microorganisms, transgenic plants, and even in vitro[18, 20, 22, 23, 36-41]. Differences in cyanophycin molecular weights and solubility have been observed in different organisms and even in organisms with genes from different bacterial strains. The different routes of cyanophycrin production and their technological and economic bottlenecks have been reviewed previously [20].

Despite this interest in cyanophycin derivatives, the applications of cyanophycin itself remain largely unexplored. Detailed knowledge of its bulk material properties and solution thermodynamics is required to understand its possible applications. Its low molecular weight, combined with its zwitterionic character, suggest an amorphous and stiff polymer with possible ionomer-like uses. Previous solubility characterization of cyanophycin, especially on the effects of increased lysine content, suggests it may also have unique applications as a surfactant, further underscoring the need to better understand its properties. This study describes relevant 
mechanical, thermal, and structural properties of recombinant soluble cyanophycin that inform its potential use as a new polymer material. The thermoresponsive behavior of soluble cyanophycin in aqueous solution is also investigated as a function of polypeptide concentration and ionic strength. The results provide the first quantitative study of the zwitterionic character of cyanophycin and its properties as a bulk material.

\section{MATERIALS AND METHODS}

Recombinant expression in $E$. coli. A previously-engineered cyanophycin synthetaseencoding gene[22] (denoted here as $c p h A_{6308} \Delta 1$ ) from Synechocystis sp. PCC6308 that showed enhanced cyanophycin production was used in this study. $c p h A_{6308} \Delta 1$ was codon-optimized for expression in E. coli (GenScript). NcoI and AflII restriction enzyme sites were included upstream and downstream of the open reading frame, respectively, to facilitate cloning into a pMMB206 expression vector. Molecular biology techniques were performed according to Sambrook and Russell[42], unless stated otherwise. Cloning and vector propagation were performed in E. coli DH10B (Invitrogen). E. coli BL21(DE3) (New England BioLabs) was used

for cyanophycin production. All cell cultures were grown in terrific broth (TB) medium with 34 $\mu \mathrm{g} \mathrm{mL} \mathrm{m}^{-1}$ chloramphenicol. Starter cultures were grown for 12 hours in $250 \mathrm{~mL}$ baffled Erlenmeyer flasks at $37^{\circ} \mathrm{C}$ with agitation at $250 \mathrm{rpm} .4 .5 \mathrm{~L}$ of TB medium supplemented with $1 \%(\mathrm{v} / \mathrm{v})$ casein hydrolysate and $0.4 \%(\mathrm{v} / \mathrm{v})$ glucose in a bioreactor was inoculated with $1 \%(\mathrm{v} / \mathrm{v})$ starter culture and grown to an optical density $\left(\mathrm{OD}_{600}\right)$ of 1.0 before induction with $1 \mathrm{mM}$ isopropyl $\beta$-D-1-thiogalactopyranoside (IPTG). Oxygen was supplied by sparging with air at a fixed flow rate under constant agitation, and $\mathrm{pH}$ was not actively controlled during expression. 
Cultures were grown for $18-22$ hours at $30^{\circ} \mathrm{C}$ and cells were harvested by centrifugation. Gene sequences and strain genotypes are included in the Supporting Information.

Cyanophycin purification. Cyanophycin was purified using a procedure adapted from the literature[22, 43]. Cell pellets were frozen at $-80{ }^{\circ} \mathrm{C}$, thawed, and resuspended in three volumes of $1.0 \mathrm{M}$ hydrochloric acid for 4 hours at $30{ }^{\circ} \mathrm{C}$ with agitation. The acidified cell mass was pelleted by centrifugation $\left(7,000 \mathrm{xg}, 20^{\circ} \mathrm{C}, 30 \mathrm{~min}\right)$. The acid supernatant was neutralized to $\mathrm{pH}$ 7 sodium hydroxide and dialyzed extensively against $>100$ volumes of deionized water at $4{ }^{\circ} \mathrm{C}$, followed by $>100$ volumes of $20 \mathrm{mM}$ ammonium bicarbonate at $4{ }^{\circ} \mathrm{C}$, and finally $>100$ volumes of deionized water at $4{ }^{\circ} \mathrm{C}$. Purified cyanophycin was then separated into water soluble and water insoluble fractions by centrifugation $\left(17,000 \mathrm{xg}, 25^{\circ} \mathrm{C}, 30 \mathrm{~min}\right)$, and dry materials were prepared by lyophilization, removing water and the majority of the volatile ammonium bicarbonate counterions to yield a pure zwitterionic material.

Molecular characterization of cyanophycin. Analysis of purified cyanophycin by sodium dodecyl sulfate-polyacrylamide gel electrophoresis (SDS-PAGE) was performed on 4-20\% (w/v) Mini-PROTEAN TGX gels using the Mini-PROTEAN Tetra Cell electrophoresis kit (BioRad). Gels were run for 45 minutes at $200 \mathrm{~V}$, washed with deionized water, and stained with Coomassie Brilliant R-250 Dye (BioRad).

The amino acid composition of cyanophycin was determined by using high-performance liquid chromatography (HPLC) analysis of ortho-phthalaldehyde (OPA)-modified amino acids. Lyophilized cyanophycin was incubated in $6 \mathrm{M}$ hydrochloric acid for 24 hours at $105{ }^{\circ} \mathrm{C}$, followed by drying under vacuum at room temperature. The hydrolysate was dissolved in $0.1 \mathrm{M}$ hydrochloric acid at $0.5 \mathrm{~g} / \mathrm{L}$ and clarified by centrifugation ( $5 \mathrm{~min}$ at $21,000 \mathrm{xg}$ ). $2.5 \mu \mathrm{L}$ of borate buffer (0.4 M boric acid, $\mathrm{pH} 10.4), 0.5 \mu \mathrm{L}$ of hydrolysate, and $0.5 \mu \mathrm{L}$ OPA stock solution (20 
$\mathrm{g} / \mathrm{L}$ in 90 parts methanol, 10 parts borate buffer, and 1 part 3-mercaptopropionic acid) were mixed using an autosampler, incubated for 120 seconds, and mixed with $32 \mu \mathrm{L}$ diluent buffer (1.5 $\mathrm{mL} 85 \%$ phosphoric acid in $100 \mathrm{~mL}$ running buffer). $30 \mu \mathrm{L}$ of this mixture was then immediately injected onto a reversed-phase C18 column $(3.5 \mu \mathrm{m}, 4.6 \times 75 \mathrm{~mm}$, Agilent $)$ operating at $40^{\circ} \mathrm{C}$ with a flow rate of $1.0 \mathrm{~mL} / \mathrm{min} .10 \mathrm{mM}$ sodium phosphate dibasic and $10 \mathrm{mM}$ sodium tetraborate ( $\mathrm{pH} 8.2)$ was used as the running buffer (A), and acetonitrile-methanol-water $(45 \%, 45 \%$, and $10 \%, v / v$, respectively) was used as the elution buffer (B). The elution gradient was as follows: $0 \mathrm{~min}, 20 \% \mathrm{~B} ; 5.0 \mathrm{~min}, 60 \% \mathrm{~B} ; 9.5 \mathrm{~min}, 60 \% \mathrm{~B} ; 10.0 \mathrm{~min}, 20 \% \mathrm{~B}$. OPAmodified amino acids were monitored at $338 \mathrm{~nm}$ (absorbance) and confirmed at $450 \mathrm{~nm}$ (fluorescence) using a G1315A diode array detector (Agilent). Linear calibration of chromatogram peak area to amino acid concentration $\left(\mathrm{R}^{2}>0.98\right)$ was performed using chromatographically-pure amino acids (Sigma-Aldrich). Cyanophycin composition was determined by taking the ratio of aspartic acid, arginine, and lysine concentration to the sum of all three in each sample. Each sample was analyzed in triplicate.

Material characterization of cyanophycin. Wide-angle X-ray scattering data were collected on lyophilized water-soluble cyanophycin powder using a Bruker D8 X-ray Diffractometer. Powder and solution-cast cyanophycin samples were analyzed using small-angle $\mathrm{X}$-ray scattering (SAXS) at Beamline 7.3.3 of the Advanced Light Source (ALS) at Lawrence Berkeley National Laboratory (LBNL). The solution-cast sample was prepared by solubilizing cyanophycin in water at high concentration $(10-20 \% \mathrm{v} / \mathrm{v})$ and repeatedly casting (3 - 4 times) into sample holders to produce a uniform disc about $1 \mathrm{~mm}$ in thickness. Samples were dried under vacuum overnight and annealed at $200{ }^{\circ} \mathrm{C}$ for 2 hours, excluding heating and cooling, while under vacuum. SAXS data were collected and corrected for empty-cell and dark-field scattering. 
Thermal properties of the purified cyanophycin were analyzed using thermogravimetric analysis (TGA) and differential scanning calorimetry (DSC). Thermogravimetric measurements were performed using a TA Instruments Discovery TGA under air with a heating rate of 20 ${ }^{\circ} \mathrm{C} / \mathrm{min}$ from 30 to $750{ }^{\circ} \mathrm{C}$. DSC was performed using a TA Instruments Discovery DSC with a heating rate of $10{ }^{\circ} \mathrm{C} / \mathrm{min}$ by cycling from $-20{ }^{\circ} \mathrm{C}$ to $200{ }^{\circ} \mathrm{C}$ and back twice, with an isothermal dwell of 5 min at each end.

For mechanical testing, purified soluble cyanophycin was pressed into cylindrical compression test specimens with 2-mm thickness using a 1/4,'-diameter dry pressing die (MTI Corporation). Samples were compressed at 2.0 metric tons and $100^{\circ} \mathrm{C}$ for 20 minutes, and extracted from the press after rapid cooling to room temperature. Mechanical testing was performed using a Zwick Z05 machine equipped with a $10 \mathrm{kN}$ load cell and at a compression rate of $1 \mathrm{~mm} / \mathrm{min}$.

Characterization of cyanophycin in solution. Analysis of the upper critical solution temperature (UCST) and lower critical solution temperature (LCST) of cyanophycin was performed on purified soluble cyanophycin suspended in deionized water at multiple concentrations. Optical transmission at $700 \mathrm{~nm}$ was monitored using a UV-Vis spectrometer (Cary 50) as the temperature was cycled between $3{ }^{\circ} \mathrm{C}$ to $60{ }^{\circ} \mathrm{C}$ at $1.0{ }^{\circ} \mathrm{C} / \mathrm{min}$. On the third heating cycle, the temperatures corresponding to the inflection point of the transmission were taken to be the transition temperatures.

\section{RESULTS AND DISCUSSION}

Recombinant cyanophycin granule protein (CGP) was produced through microbial fermentation at a 4.5-liter scale, with a protein yield of $970 \pm 80 \mathrm{mg} / \mathrm{L}$ of culture (averaged over three fermentation batches) after acid extraction. In general, recombinant cyanophycin is 
separated into soluble in insoluble forms via fractionation processes that vary slightly across different studies[18, 32]. Here, soluble cyanophycin is denoted as the acid-extracted polypeptide dialyzed into water that remains dissolved at $25^{\circ} \mathrm{C}$, and it makes up the majority of the total protein extracted $(68 \pm 7 \% \mathrm{wt})$. This purified soluble cyanophycin fraction is isolated as white solids, while the insoluble fraction is isolated as a mixture of white and denser brown-colored solids (Figure 1a).

Multiple batches of soluble and insoluble cyanophycin were blended together to obtain averaged chemical, physical, and mechanical properties. SDS-PAGE analysis (Figure 1b) revealed that both cyanophycin fractions are polydisperse, with a molecular mass distribution of about 20 to $25 \mathrm{kDa}$ for the insoluble fraction and about 8 to $20 \mathrm{kDa}$ for the soluble fraction, as determined by comparison to protein standards. The molecular weight range for the insoluble fraction is similar to that obtained in other E. coli fermentation studies, while the soluble fraction is more polydisperse, as significant amounts of the protein has lower molecular weight than previously reported [18, 32]. Consistent with known polyzwitterion behavior[44], cyanophycin's solubility in water appears to decrease with increasing molar mass. The presence of lower molecular weight cyanophycin therefore may have contributed towards larger fractions of soluble polymer, although differences in amino acid compositions is also a contributing factor which cannot be decoupled. 
(a)

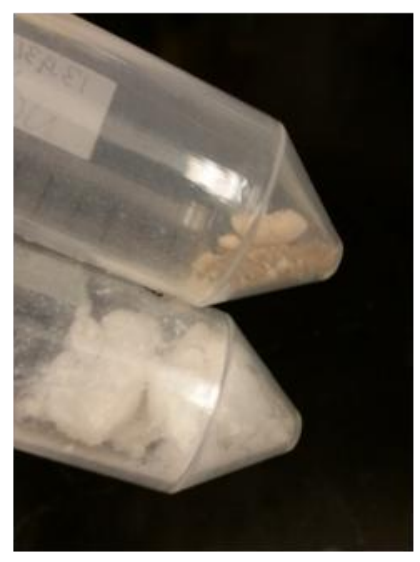

(c)<smiles>CNC(CC(=O)NC(CCCNC(=N)N)C(=O)O)C(C)=O</smiles>

(b)

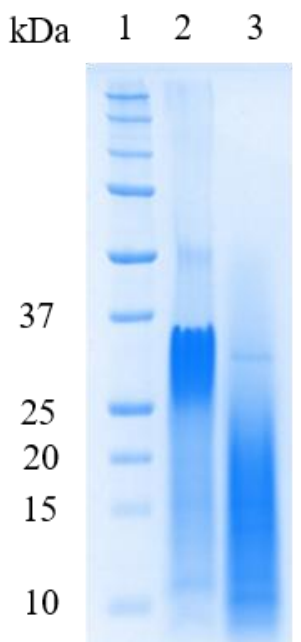

(d)

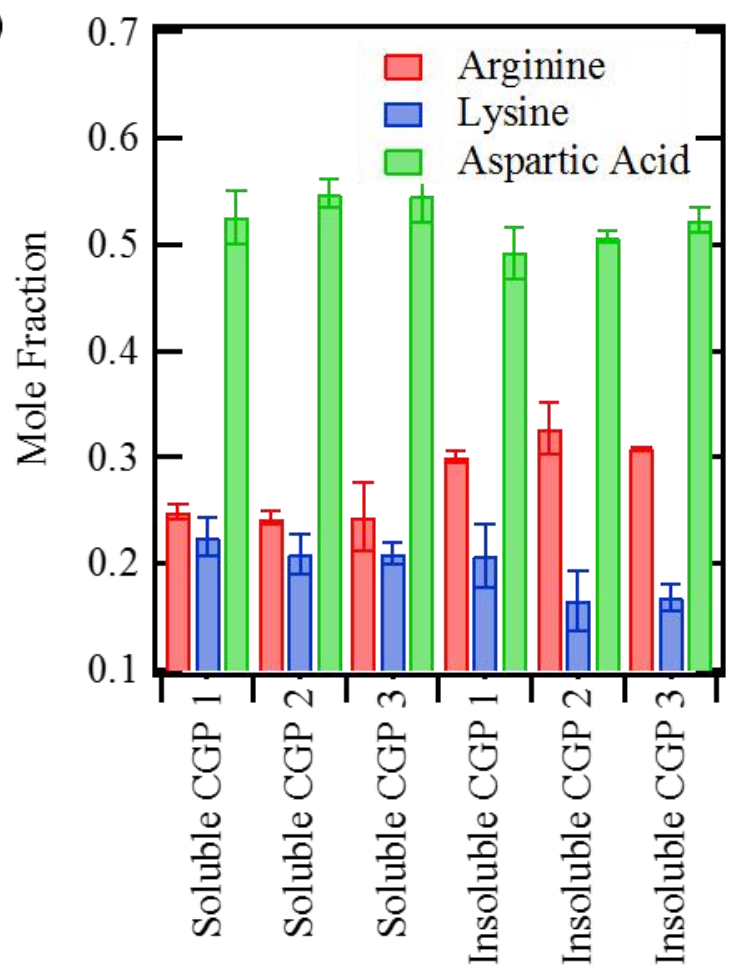

Figure 1. (a) Lyophilized soluble cyanophycin (CGP) (white powder, bottom) and insoluble CGP (brown denser solids, top) after fractionation at $25{ }^{\circ} \mathrm{C}$ in water. (b) SDS-PAGE of CGP: Lane 1, molecular mass markers; Lane 2, insoluble CGP; Lane 3, soluble CGP. (c) Chemical structure of a cyanophycin monomer dipeptide, with arginine (left) or lysine side chains (right). 
(d) Amino acid composition of soluble and insoluble cyanophycin. Hydrolysis was performed in triplicate.

Amino acid compositions of soluble and insoluble cyanophycin fractions were determined through HPLC analysis of OPA-derivatized cyanophycin hydrolysates. The results indicate that half of the polypeptide is comprised of aspartic acid, while the other half consists of arginine and lysine (Figure 1d). This is consistent with the known chemical structure of cyanophycin, where each monomer is composed of a $\beta$-functionalized aspartic acid linked to a second amino acid, typically either arginine or lysine (Figure 1c). The soluble fraction is made up of $54.2 \pm 1.9 \%$ aspartic acid, $24.5 \pm 0.7 \%$ arginine, and $21.3 \pm 2 \%$ lysine, while the insoluble fraction is made up of $51.0 \pm 1.9 \%$ aspartic acid, $31.4 \pm 1.7 \%$ arginine, and $17.7 \pm 3.1 \%$ lysine. Soluble cyanophycin has a larger lysine to arginine ratio $(0.87 \pm 0.03)$ than insoluble cyanophycin $(0.58 \pm 0.10)$. Similar trends have been previously observed by Frommeyer et al., and the larger proportion of arginine in insoluble cyanophycin was presumed to be a cause of its insolubility[32], as guanidinium groups on arginine side chains can form more hydrogen bonds with carbonyl groups than primary amines on lysine side chains[45]. The improved solubility behavior observed in lysine-rich water-soluble cyanophycin could therefore potentially be due to disrupted hydrogen bonding and decreased intramolecular interactions, in addition to its lower molecular weight.

Solution behavior of cyanophycin was examined using turbidimetry, where upper critical solution temperature (UCST) and lower critical solution temperature (LCST) type transitions were detected. Due to the negatively charged $\alpha$-carboxyl group and the positively charged side chain groups of arginine and lysine at neutral conditions, the polypeptide has extensive intrachain associations from zwitterionic and hydrogen bonds on the same chain, and intra-group 
associations from ion pairs within each monomer. The soluble fraction exhibits both UCST and LCST in dilute solutions, as evidenced in the two sharp transitions in solution transmission upon heating or cooling (Figure 2). To investigate the reversibility of the UCST and LCST behaviors, cyanophycin in solution was subjected to multiple heating and cooling cycles. A small amount of precipitate was formed irreversibly after the first and second temperature cycles, possibly due to the presence of impurities. After three cycles of heating and cooling, phase separation behavior remains consistent across additional heating and cooling cycles (Supporting Information S1). From the third heating cycle, temperatures corresponding to the inflection points were taken as transition temperatures.

Thermal transition behavior of the material is dependent on its concentration and the ionic strength of the solution. The temperature window at which cyanophycin solubility is highest is the widest at low concentrations and narrowest at around $10 \mathrm{mg} / \mathrm{mL}$, where a peak in the UCST type transition temperature is observed (Figure 2a, b). In polyzwitterions, the phase space where increasing concentration leads to lowering of UCST transition temperatures was hypothesized to be a result of enhanced solubilization induced by intermolecular interactions. Small amounts of additional polymer replaces intramolecular associations with intermolecular ones, which lead to an expansion in chain conformation and subsequently an increase in solubility[46]. 
(a)

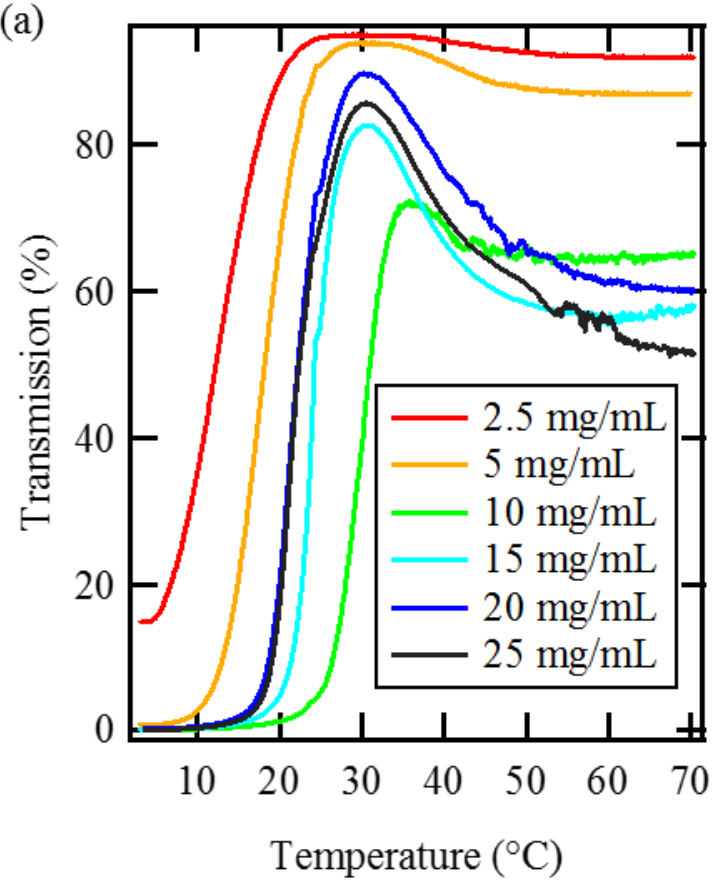

(b)

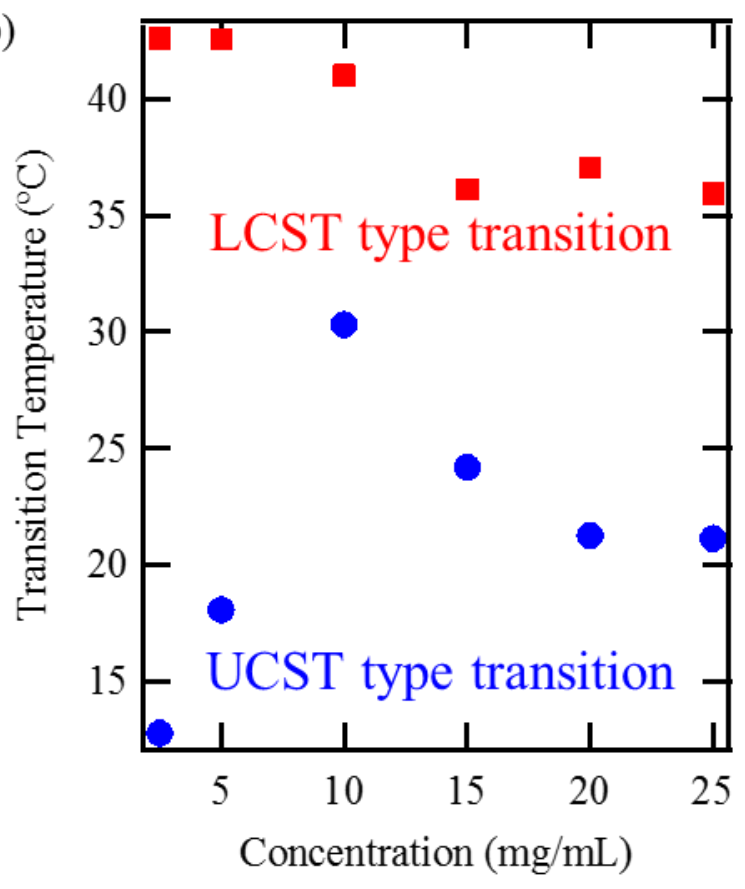

Figure 2. (a) Change in optical transmission of cyanophycin in water on the third heating ramp at various concentrations. (b) Transition temperatures of cyanophycin in water as a function of protein concentration. Transition temperatures are defined as inflection point temperatures.

Since fractionation in this study was performed on very dilute protein solutions at $25{ }^{\circ} \mathrm{C}$, UCST type thermal transitions for dilute solutions are necessarily below $25{ }^{\circ} \mathrm{C}$. Protein chains with high UCST transition temperatures at similar concentrations would be isolated in the insoluble fraction (Supporting Information S2). No LCST transitions were observed for the insoluble fraction in the temperature range of $3-80{ }^{\circ} \mathrm{C}$.

Previous reports on cyanophycin solution behavior have mainly focused on the insoluble fraction, where the effects of temperature and salt concentration on solubility were investigated[44]. Through temperature gradient separation of insoluble cyanophycin, Wiefel et al. showed that the polypeptide is a polydisperse polymer with a significant solubilization temperature distribution, where higher lysine content corresponds to a lower solubilization 
temperature (UCST) [31]. Fuser et al. have shown that inorganic salts can increase solubilization of insoluble cyanophycin, which remains soluble when salt ions are bound to the polypeptide[29]. This thermal sensitivity and solubility enhancement in the presence of salt is consistent with the behavior of commonly investigated polyzwitterions. In this work, the solution behavior of soluble cyanophycin is explored. Interestingly, the lysine-rich soluble fraction exhibits dual UCST and LCST behavior, while Wiefel et al. also reported only one UCST type transition for the insoluble fraction within similar temperature ranges[31].

The observed dual transition behavior of soluble cyanophycin in aqueous solution can be explained by its amino acid composition and structure. Quiroz and Chilkoti have conducted extensive studies on amino acid sequence dependent phase behavior in intrinsically disordered proteins and found patterns in sequences that undergo phase transitions[47]. Resilin, a protein similar to cyanophycin in that it has an almost equal number of positively- and negativelycharged residues, serves as an example of a polypeptide with both UCST and LCST behavior. Arginine comprises the majority of its cationic residues, and upon deprotonation of these residues at high $\mathrm{pH}$, rec1-resilin loses its UCST behavior[47]. Electroneutrality therefore was proposed to be a requirement for UCST behavior in polypeptides, and arginine as the cationic residue drives UCST phase transitions more strongly when compared to lysine[48]. At $\mathrm{pH}-$ neutral conditions, cyanophycin should have near zero net charge, leading to UCST-type transitions in both soluble as well as insoluble fractions. The occurrence of UCST-type transitions at lower temperatures for lysine-rich soluble cyanophycin fraction can be attributed to fewer guanidinium groups in their side chains as compared to the insoluble fraction.

Both the lower and upper transition temperatures are decreased upon a slight increase in ionic strength, although the effects of ionic strength appear more pronounced in the UCST type 
transition (Figure 3). This behavior is consistent with previous observations where waterinsoluble cyanophycin was partly solubilized in simple salt solutions[29]. Salt induced decreases in UCST type transition temperatures in zwitterionic polymers can be attributed to reduced monomer interactions due to charge screening[49]. The weaker dependence of LCST-type transitions on temperature and ionic strength suggests that there are different types of protein interactions that lead to phase transitions. Unlike the UCST-type transitions that are likely driven by ionic interactions, the LCST observed may be better explained by the hydrophobic effect in unfolded polypeptides[50]. Although cyanophycin is made up of polar residues, backbone hydrogen bonding has been shown to decrease polypeptide water solubility[51]. Its significant arginine fraction contributes to the charged character of the polypeptide without decreasing its hydrophobicity, as opposed to other charged residues[52]. At this transition, the negative entropy of mixing dominates, and the polypeptide chains collapse and phase separate.

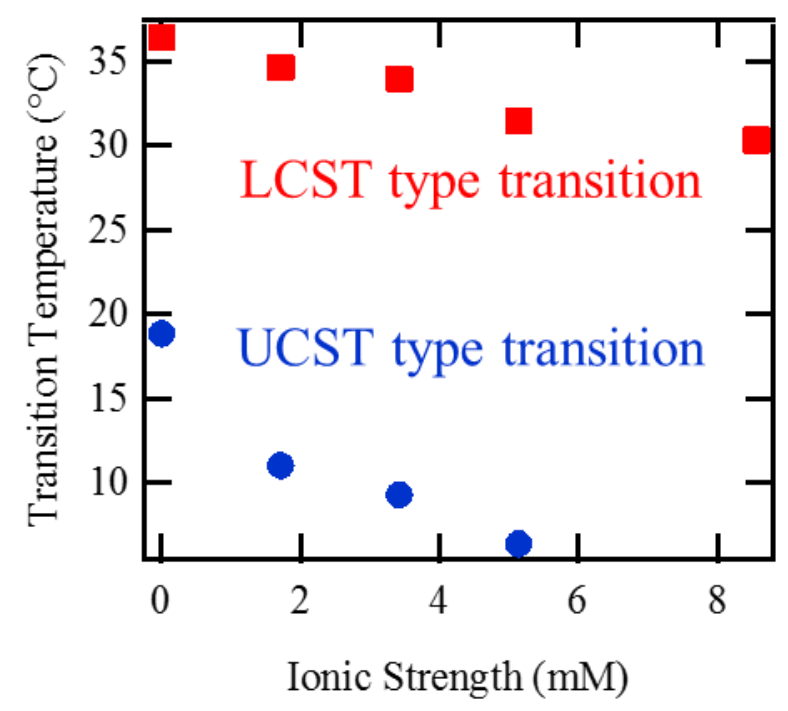

Figure 3. Transition temperatures of $10 \mathrm{mg} / \mathrm{mL}$ cyanophycin in sodium chloride solutions as a function of ionic strength. 
The smaller effect of salt on the LCST is consistent with observations on other thermally responsive systems. LCST dependence on ionic strength has been widely explored in poly(Nsicopropylacrylamide) (PNIPAM), a polymer with a peptide bond in its monomer unit. Salts typically reduce its LCST through interactions with water involved in hydrogen bonding with the amide and hydrophobic hydration, and the effect of anions follows Hoffmeister series[53]. A block copolymer of PNIPAM and zwitterionic polysulfobetaine has been shown to exhibit both UCST and LCST in water. Upon sodium chloride addition, UCST of this copolymer decreases and disappears entirely even at relatively low salt concentrations, while the LCST decreases in a more gradual manner[54].

In general, the composition of cyanophycin suggests that both UCST and LCST behaviors are expected in aqueous solutions. It should be noted, however, that because it is non-ribosomally synthesized, cyanophycin exhibits variability in both molecular weight and composition, thus potentially leading to batch-dependent differences in transition temperatures.

In the dry state, cyanophycin forms an amorphous solid, consistent with observations of purely synthetic zwitterionic polymers like polymethacrylate and polyvinyl sulfobetaines, which depending on their molecular architecture, may form microphase separated ionic and hydrophobic structures $[55,56]$. X-ray diffraction of cyanophycin reveals a broad halo with a peak at approximately $15 \mathrm{~nm}^{-1}$ and a shoulder at $7.5 \mathrm{~nm}^{-1}$ (Figure $4 \mathrm{a}$ ), corresponding to dspacings of $0.42 \mathrm{~nm}$ and $0.83 \mathrm{~nm}$, respectively. This is similar to typical wide-angle X-ray scattering patterns of proteins where two peaks are usually observed: one at $0.45 \mathrm{~nm}$ as a result of interstrand or backbone hydrogen bonding, and another at $1 \mathrm{~nm}$ corresponding to inter-sheet or inter-helix hydrogen bonding[57]. Notably, any sort of ionic crystal structure is absent, indicating that the charged side groups of the cyanophycin are unable to crystallize in the solid 
state. Despite the lack of crystallinity, the absence of residual salt in the polypeptide is confirmed through other techniques since up to stoichiometric amounts of salt have previously been shown to be miscible with polyzwitterions and remain amorphous due to strong ion-dipole interactions[58, 59]. Cyanophycin does not exhibit long range ordering (Figure $4 \mathrm{~b}$ ). The small angle X-ray scattering data exhibits a power law decay with an exponent of $3.66 \pm 0.11$, close to the exponent of 4.0 that indicates a disordered two phase structure[60]. The polypeptide therefore likely has a disordered, macrophase-separated structure with voids that remain kinetically trapped even after sample casting and annealing. The lack of microstructure is independent of the sample processing method, as similar results were obtained for samples in powder form and samples that were solution cast from water. In addition, cyanophycin in solution does not form ordered structures (Supplementary S3). Small shifts in the scattering curves were observed in the low-q region in accordance with transitions of the protein from insoluble to soluble to insoluble as temperature is increased. 
(a)

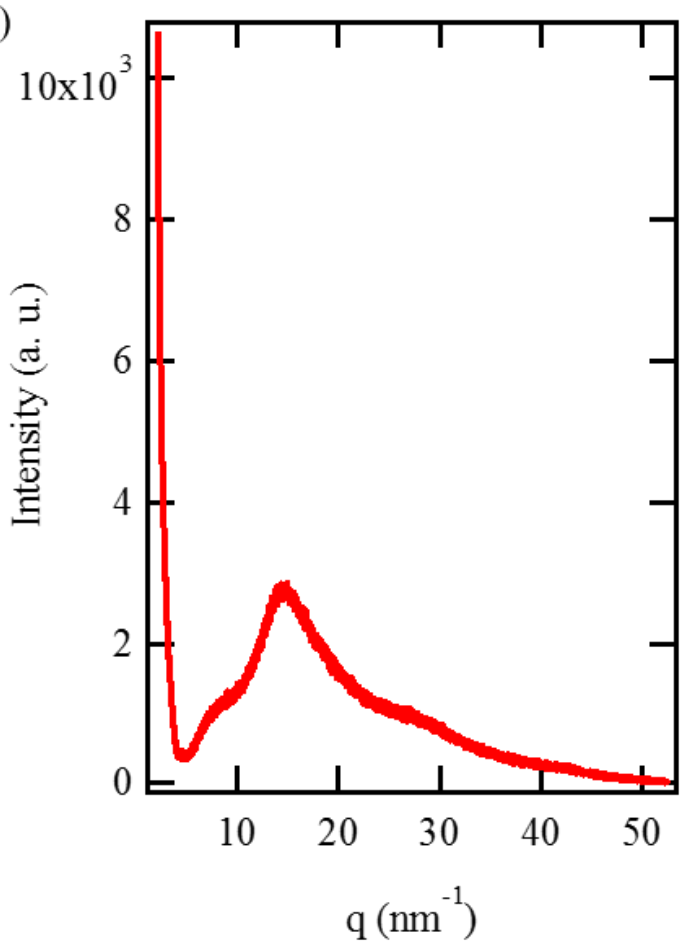

(b)

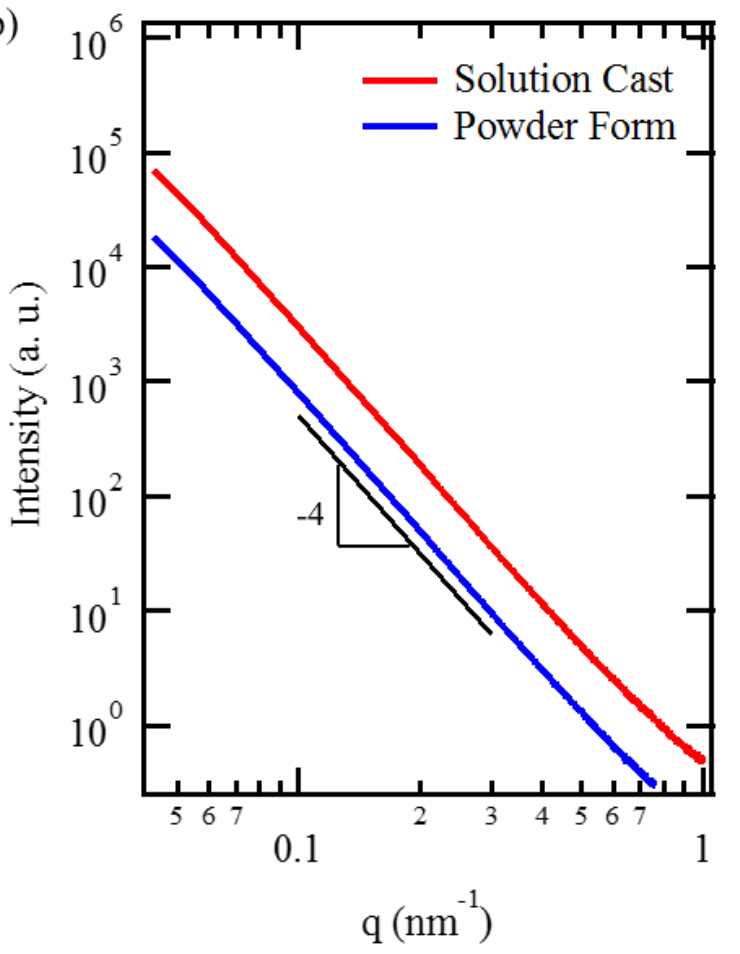

Figure 4. (a) X-ray diffraction pattern of cyanophycin powder. (b) Small-angle X-ray scattering data of annealed powder and solution cast cyanophycin on a log-log scale (curves are offset for clarity).

Thermal properties of cyanophycin were examined to determine its decomposition temperature and to detect any phase transitions in the solid state. TGA results show that the polypeptide is thermally stable to about $200{ }^{\circ} \mathrm{C}$ under air, and is completely pyrolyzed upon reaching $700{ }^{\circ} \mathrm{C}$ (Figure 5a), indicating an absence of non-volatile salts in the material. Mass loss below $100{ }^{\circ} \mathrm{C}$ ( $8-9 \%$ for soluble cyanophycin, $5-6 \%$ for insoluble cyanophycin) suggests the presence of tightly-bound water that remains even after lyophilization. As expected for dehydrated proteins, DSC shows that both cyanophycin fractions do not undergo a glass transition or melting transition within the accessible range of temperature due to strong intermolecular interactions and the lack of mobility of polymer chains (Figure 5b). 
(a)

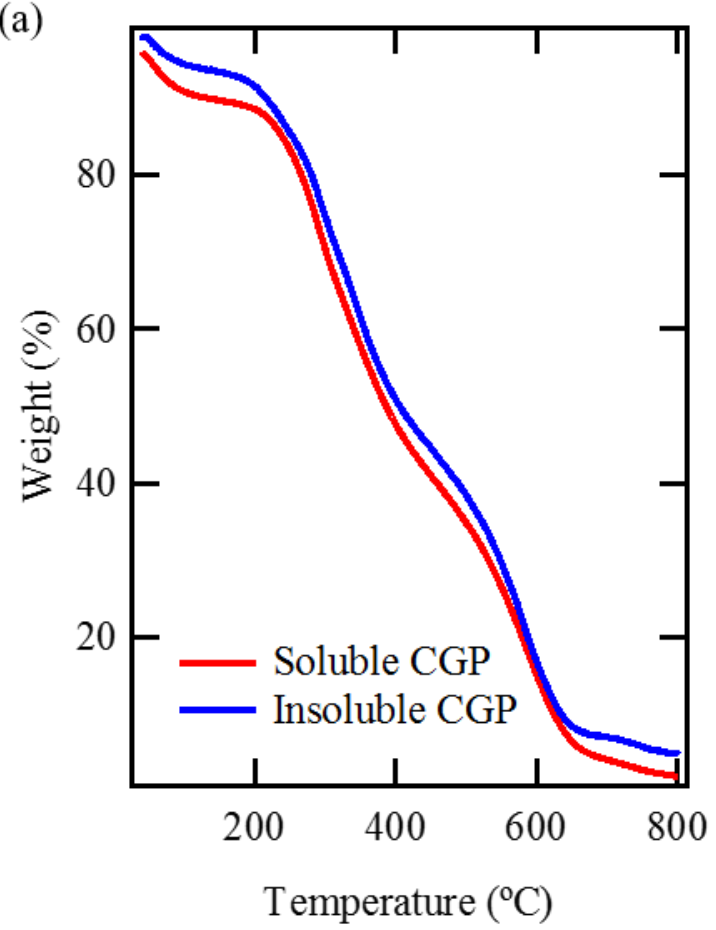

(b)

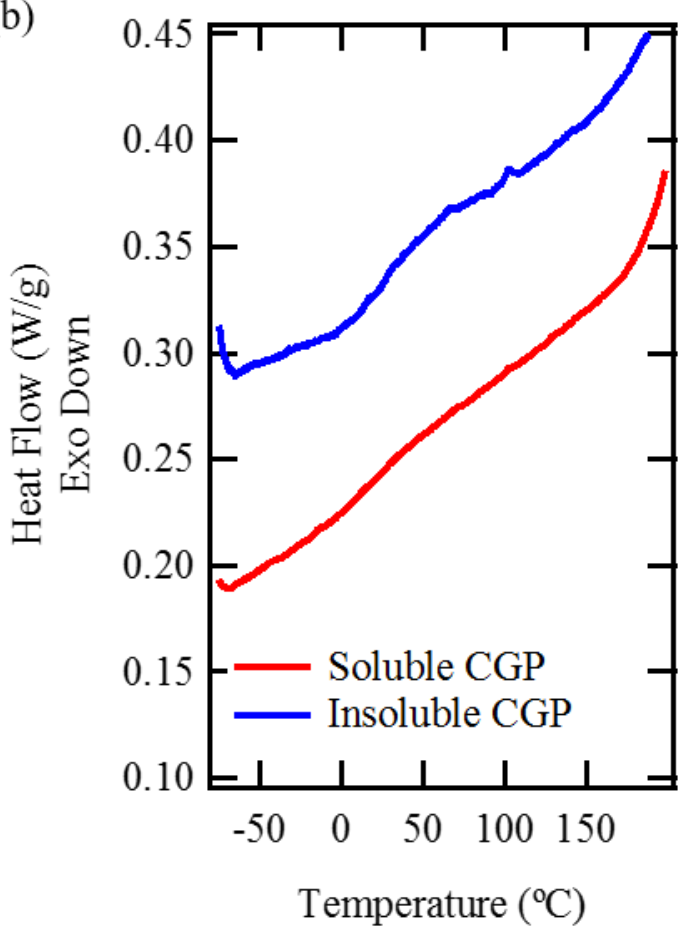

Figure 5. (a) TGA traces and (b) second DSC heating scan of soluble and insoluble cyanophycin (curves are offset for clarity).

The mechanical behavior of pure, unmodified cyanophycin was studied through compression testing due to the brittleness of the cyanophycin. Mechanical test specimens were prepared using compression molding to fuse the polypeptide into pellets at elevated pressures and temperatures (Figure 6a). As shown in the compression stress - strain curves (Figure 6b), the material is stiff and undergoes brittle failure at small strains. Averaged over seven samples, the Young's modulus, ultimate compressive strength, and strain-at-break are $560 \pm 70 \mathrm{MPa}, 78 \pm 20 \mathrm{MPa}$ and $17 \pm 4 \%$, respectively. The mechanical behavior of compression molded cyanophycin is comparable to those reported for other unplasticized polypeptides, which are known to be rigid and brittle due to the large number of chain interactions[61, 62]. Compression molded soy protein isolate is reported to have Young's modulus, maximum stress, and strain at break at approximately $1.7 \mathrm{GPa}, 22 \mathrm{MPa}$, and $1.8 \%$, respectively[63]. 
(a)

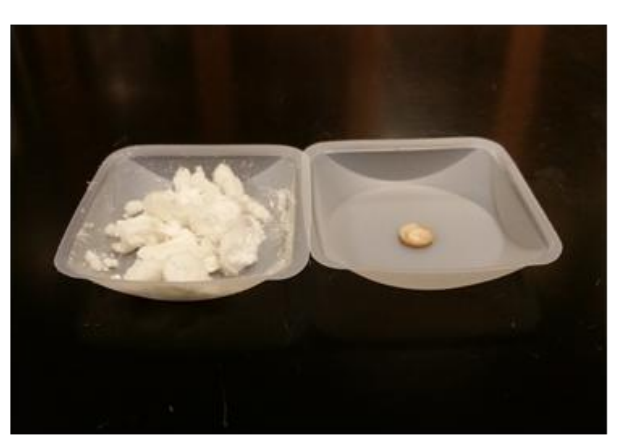

(b)

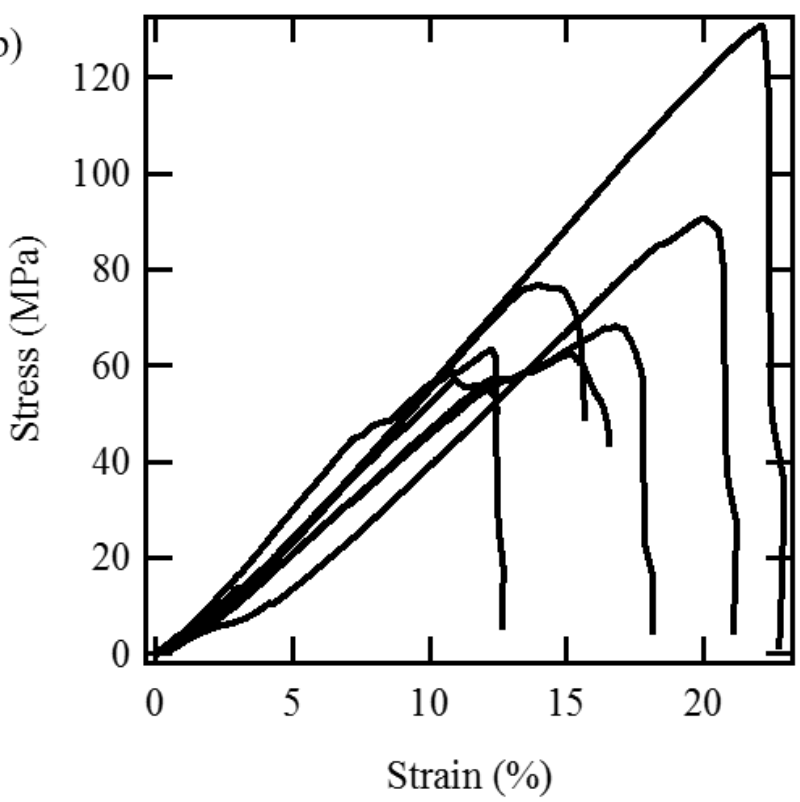

Figure 6. (a) Cyanophycin powder and compressed pellet. (b) Compression stress-strain curves of cyanophycin pellets tested at $1 \mathrm{~mm} / \mathrm{min}$.

Although the results suggest that pure cyanophycin is too brittle for most applications as a material, its zwitterionic character makes it an interesting candidate as a component in zwitterionomeric copolymers. In these copolymers, ionic associations between chains serve as physical crosslinks that undergo rupture upon material deformation[59]. The reversibility of these crosslinks enhances the toughness and fatigue resistance of the material as energy is dissipated when bonds are broken and reformed[64, 65]. Hydrogels made up of zwitterionic random copolymers have been shown to exhibit superior elastomeric performance when compared to cationic analogues. In other examples, zwitterionization of linear polyurethane chain extenders appears to enhance microphase separation, hard domain cohesion, and mechanical properties due to aggregation of the ionic groups[66]. As a block ionomer complex, cyanophycin could potentially be used to toughen resins. Various well known protein 
conjugation strategies $[67,68]$ can be applied to cyanophycin in the synthesis of hybrid materials that combine the strengths of cyanophycin with the versatility of synthetic polymers. In addition, brittleness of cyanophycin can be reduced through the addition of small polar molecules as plasticizers, which reduces inter and intramolecular protein interactions and allows the material to be more processable[69].

\section{CONCLUSION}

Cyanophycin is an amorphous, glassy polyzwitterion with a glass transition beyond its thermal decomposition temperature. The material is stiff and brittle in the dry state. The water-soluble form of cyanophycin is thermoresponsive in dilute solution, exhibiting upper and lower critical solution behavior that is a function of ionic strength. Given its glassy nature and good thermostability, cyanophycin may be attractive as a sustainably sourced and biodegradable material that could be used to synthesize zwitterionomeric copolymers or as reinforcing fillers. The high charge density and the thermoresponsiveness of cyanophycin potentially could be harnessed to design hybrid materials with improved mechanical and thermal properties. Cyanophycin is also readily modified or derivatized due to the presence of a number of reactive functional handles in its amino acid side chains, which could be exploited to create a range of cyanophycin-derived sustainable polymers.

\section{ASSOCIATED CONTENT}

Supporting Information. Strains and genotypes; gene sequence for $c p h A_{6308} \Delta l$; phase transitions of cyanophycin in solution across multiple cycles; insoluble cyanophycin solution behavior; SAXS of cyanophycin in solution. 


\section{ACKNOWLEDGMENT}

This work was supported by Massachusetts Institute of Technology (MIT) \& Masdar Institute of Science and Technology (MI) Flagship Project (Biorefinery: Integrated Sustainable Processes for Biomass Conversion to Biomaterials, Biofuels, and Fertilizer) and by the National Science Foundation through the Synthetic Biology Engineering Research Center (Synberc; Grant No. EEC-0540879). The authors acknowledge the Institute for Soldier Nanotechnologies for providing the infrastructure for TGA, DSC, compression molding, and mechanical testing work. SAXS measurements were performed at Beamline 7.3.3 of the Advanced Light Source (ALS) at

Lawrence Berkeley National Laboratory (LBNL), and XRD experiments at the Roman lab at MIT. The authors thank Matt Glassman, Christopher Lam, Guokui Qin, Yekaterina Tarasova, Helen Luo, and Lionel Moh for helpful discussions and guidance in instrumentation use.

\section{ABBREVIATIONS}

\section{REFERENCES}

[1] A.L. Andrady, M.A. Neal, Applications and societal benefits of plastics, Philosophical Transactions of the Royal Society of London B: Biological Sciences 364(1526) (2009) 19771984.

[2] J. Hopewell, R. Dvorak, E. Kosior, Plastics recycling: challenges and opportunities, Philosophical Transactions of the Royal Society of London B: Biological Sciences 364(1526) (2009) 2115-2126. 
[3] D.K. Barnes, F. Galgani, R.C. Thompson, M. Barlaz, Accumulation and fragmentation of plastic debris in global environments, Philosophical Transactions of the Royal Society of London B: Biological Sciences 364(1526) (2009) 1985-1998.

[4] K.L. Law, S. Morét-Ferguson, N.A. Maximenko, G. Proskurowski, E.E. Peacock, J. Hafner, C.M. Reddy, Plastic accumulation in the North Atlantic subtropical gyre, Science 329(5996) (2010) 1185-1188.

[5] R.C. Thompson, Y. Olsen, R.P. Mitchell, A. Davis, S.J. Rowland, A.W. John, D. McGonigle, A.E. Russell, Lost at sea: where is all the plastic?, Science 304(5672) (2004) 838-838.

[6] R.C. Thompson, S.H. Swan, C.J. Moore, F.S. Vom Saal, Our plastic age, Philosophical Transactions of the Royal Society of London B: Biological Sciences 364(1526) (2009) 19731976.

[7] G.E. Luckachan, C.K.S. Pillai, Biodegradable Polymers- A Review on Recent Trends and Emerging Perspectives, J Polym Environ 19(3) (2011) 637-676.

[8] E. Chiellini, R. Solaro, Biodegradable polymeric materials, Adv Mater 8(4) (1996) 305-313.

[9] L.S. Nair, C.T. Laurencin, Biodegradable polymers as biomaterials, Progress in polymer science 32(8) (2007) 762-798.

[10] M. Obst, A. Steinbüchel, Microbial degradation of poly (amino acid) s, Biomacromolecules 5(4) (2004) 1166-1176.

[11] A.J. Ragauskas, C.K. Williams, B.H. Davison, G. Britovsek, J. Cairney, C.A. Eckert, W.J. Frederick, J.P. Hallett, D.J. Leak, C.L. Liotta, The path forward for biofuels and biomaterials, science 311(5760) (2006) 484-489.

[12] M. Parikka, Global biomass fuel resources, Biomass and Bioenergy 27(6) (2004) 613-620. 
[13] S. Naik, V.V. Goud, P.K. Rout, A.K. Dalai, Production of first and second generation biofuels: a comprehensive review, Renewable and Sustainable Energy Reviews 14(2) (2010) $578-597$.

[14] R. Saxena, D. Adhikari, H. Goyal, Biomass-based energy fuel through biochemical routes: a review, Renewable and Sustainable Energy Reviews 13(1) (2009) 167-178.

[15] G.W. Huber, S. Iborra, A. Corma, Synthesis of transportation fuels from biomass: chemistry, catalysts, and engineering, Chemical reviews 106(9) (2006) 4044-4098.

[16] B.H. Rehm, Bacterial polymers: biosynthesis, modifications and applications, Nature Reviews Microbiology 8(8) (2010) 578-592.

[17] L. Shen, E. Worrell, M. Patel, Present and future development in plastics from biomass, Biofuels, Bioproducts and Biorefining 4(1) (2010) 25-40.

[18] W.C. Tseng, T.Y. Fang, C.Y. Cho, P.S. Chen, C.S. Tsai, Assessments of growth conditions on the production of cyanophycin by recombinant Escherichia coli strains expressing cyanophycin synthetase gene, Biotechnology progress 28(2) (2012) 358-363.

[19] F. Oppermann-Sanio, A. Steinbüchel, Occurrence, functions and biosynthesis of polyamides in microorganisms and biotechnological production, Naturwissenschaften 89(1) (2002) 11-22. [20] H. Mooibroek, N. Oosterhuis, M. Giuseppin, M. Toonen, H. Franssen, E. Scott, J. Sanders, A. Steinbüchel, Assessment of technological options and economical feasibility for cyanophycin biopolymer and high-value amino acid production, Applied microbiology and biotechnology $77(2)(2007)$ 257-267.

[21] K. Lin, Y. Elbahloul, A. Steinbüchel, Physiological conditions conducive to high cell density and high cyanophycin content in Ralstonia eutropha strain H16 possessing a KDPG 
aldolase gene-dependent addiction system, Applied microbiology and biotechnology 93(5) (2012) 1885-1894.

[22] K.M. Frey, F.B. Oppermann-Sanio, H. Schmidt, A. Steinbüchel, Technical-scale production of cyanophycin with recombinant strains of Escherichia coli, Applied and environmental microbiology 68(7) (2002) 3377-3384.

[23] J. Kroll, S. Klinter, A. Steinbüchel, A novel plasmid addiction system for large-scale production of cyanophycin in Escherichia coli using mineral salts medium, Applied microbiology and biotechnology 89(3) (2011) 593-604.

[24] A.H. Mackerras, N.M. de Chazal, G.D. Smith, Transient accumulations of cyanophycin in Anabaena cylindrica and Synechocystis 6308, Microbiology 136(10) (1990) 2057-2065. [25] R.D. Simon, Measurement of the cyanophycin granule polypeptide contained in the bluegreen alga Anabaena cylindrica, Journal of bacteriology 114(3) (1973) 1213-1216.

[26] M.M. Allen, Cyanobacterial cell inclusions, Annual Reviews in Microbiology 38(1) (1984) $1-25$.

[27] K. Ziegler, A. Diener, C. Herpin, R. Richter, R. Deutzmann, W. Lockau, Molecular characterization of cyanophycin synthetase, the enzyme catalyzing the biosynthesis of the cyanobacterial reserve material multi- L- arginyl- poly- L- aspartate (cyanophycin), European journal of biochemistry 254(1) (1998) 154-159.

[28] R. Richter, M. Hejazi, R. Kraft, K. Ziegler, W. Lockau, Cyanophycinase, a peptidase degrading the cyanobacterial reserve material multi- L- arginyl- poly- L- aspartic acid (cyanophycin), European Journal of Biochemistry 263(1) (1999) 163-169. 
[29] G. Füser, A. Steinbüchel, Investigations on the solubility behavior of cyanophycin.

Solubility of cyanophycin in solutions of simple inorganic salts, Biomacromolecules 6(3) (2005) $1367-1374$.

[30] E. Aboulmagd, F.B. Oppermann-Sanio, A. Steinbüchel, Molecular characterization of the cyanophycin synthetase from Synechocystis sp. strain PCC6308, Archives of microbiology 174(5) (2000) 297-306.

[31] L. Wiefel, A. Steinbüchel, Solubility behavior of cyanophycin depending on lysine content, Applied and environmental microbiology 80(3) (2014) 1091-1096.

[32] M. Frommeyer, A. Steinbüchel, Increased lysine content is the main characteristic of the soluble form of the polyamide cyanophycin synthesized by recombinant Escherichia coli, Applied and environmental microbiology 79(14) (2013) 4474-4483.

[33] M. Zohuriaan- Mehr, A. Pourjavadi, H. Salimi, M. Kurdtabar, Protein- and homo poly (amino acid)- based hydrogels with super- swelling properties, Polymers for Advanced Technologies 20(8) (2009) 655-671.

[34] S.M. Thombre, B.D. Sarwade, Synthesis and biodegradability of polyaspartic acid: a critical review, Journal of Macromolecular Science, Part A 42(9) (2005) 1299-1315.

[35] R.A. Gross, B. Kalra, Biodegradable polymers for the environment, Science 297(5582) (2002) 803-807.

[36] A. Sallam, A. Steinbüchel, Dipeptides in nutrition and therapy: cyanophycin-derived dipeptides as natural alternatives and their biotechnological production, Applied microbiology and biotechnology 87(3) (2010) 815-828.

[37] I. Voss, S.C. Diniz, E. Aboulmagd, A. Steinbüchel, Identification of the Anabaena sp. Strain PCC7120 Cyanophycin Synthetase as Suitable Enzyme for Production of Cyanophycin in Gram- 
Negative Bacteria Like Pseudomonas p utida and Ralstonia e utropha, Biomacromolecules 5(4) (2004) 1588-1595.

[38] T. Hai, F.B. Oppermann-Sanio, A. Steinbüchel, Molecular characterization of a thermostable cyanophycin synthetase from the thermophilic cyanobacterium Synechococcus sp. strain MA19 and in vitro synthesis of cyanophycin and related polyamides, Applied and environmental microbiology 68(1) (2002) 93-101.

[39] Y. Elbahloul, K. Frey, J. Sanders, A. Steinbüchel, Protamylasse, a residual compound of industrial starch production, provides a suitable medium for large-scale cyanophycin production, Applied and environmental microbiology 71(12) (2005) 7759-7767.

[40] K. Neumann, D.P. Stephan, K. Ziegler, M. Hühns, I. Broer, W. Lockau, E.K. Pistorius, Production of cyanophycin, a suitable source for the biodegradable polymer polyaspartate, in transgenic plants, Plant Biotechnology Journal 3(2) (2005) 249-258.

[41] A. Steinle, S. Witthoff, J.P. Krause, A. Steinbüchel, Establishment of cyanophycin biosynthesis in Pichia pastoris and optimization by use of engineered cyanophycin synthetases, Applied and environmental microbiology 76(4) (2010) 1062-1070.

[42] J. Sambrook, E. Fritsch, T. Maniatis, Molecular cloning: a laboratory manual, 3 Vol, Set (NY, USA: Cold Srping Harbor Laboratory Press, Cold Spring Harbor, 2001) (1989) 2344. [43] A. Steinle, A. Steinbüchel, Establishment of a simple and effective isolation method for cyanophycin from recombinant Saccharomyces cerevisiae, Applied microbiology and biotechnology 85 (2010) 1393-1399.

[44] D. Schulz, D. Peiffer, P. Agarwal, J. Larabee, J. Kaladas, L. Soni, B. Handwerker, R. Garner, Phase behaviour and solution properties of sulphobetaine polymers, Polymer 27(11) (1986) 1734-1742. 
[45] C. Borders, J.A. Broadwater, P.A. Bekeny, J.E. Salmon, A.S. Lee, A.M. Eldridge, V.B. Pett, A structural role for arginine in proteins: multiple hydrogen bonds to backbone carbonyl oxygens, Protein Science 3(4) (1994) 541-548.

[46] D.N. Schulz, D.G. Peiffer, P.K. Agarwal, J. Larabee, J.J. Kaladas, L. Soni, B. Handwerker, R.T. Garner, Phase-Behavior and Solution Properties of Sulfobetaine Polymers, Polymer 27(11) (1986) 1734-1742.

[47] F.G. Quiroz, A. Chilkoti, Sequence heuristics to encode phase behaviour in intrinsically disordered protein polymers, Nature materials (2015).

[48] A.S. Holehouse, R.V. Pappu, Protein polymers: Encoding phase transitions, Nature materials 14(11) (2015) 1083-1084.

[49] A.V. Dobrynin, R.H. Colby, M. Rubinstein, Polyampholytes, Journal of Polymer Science Part B: Polymer Physics 42(19) (2004) 3513-3538.

[50] V. Aseyev, H. Tenhu, F.M. Winnik, Non-ionic thermoresponsive polymers in water, Self Organized Nanostructures of Amphiphilic Block Copolymers II, Springer2010, pp. 29-89. [51] D.P. Teufel, C.M. Johnson, J.K. Lum, H. Neuweiler, Backbone-driven collapse in unfolded protein chains, Journal of molecular biology 409(2) (2011) 250-262.

[52] D.W. Urry, D. Gowda, T.M. Parker, C.H. Luan, M.C. Reid, C.M. Harris, A. Pattanaik, R.D. Harris, Hydrophobicity scale for proteins based on inverse temperature transitions, Biopolymers 32(9) (1992) 1243-1250.

[53] Y.J. Zhang, S. Furyk, D.E. Bergbreiter, P.S. Cremer, Specific ion effects on the water solubility of macromolecules: PNIPAM and the Hofmeister series, Journal of the American Chemical Society 127(41) (2005) 14505-14510. 
[54] J. Virtanen, M. Arotcarena, B. Heise, S. Ishaya, A. Laschewsky, H. Tenhu, Dissolution and aggregation of a poly(NIPA-block-sulfobetaine) copolymer in water and saline aqueous solutions, Langmuir 18(14) (2002) 5360-5365.

[55] R.H. Brown, A.J. Duncan, J.H. Choi, J.K. Park, T.Y. Wu, D.J. Leo, K.I. Winey, R.B. Moore, T.E. Long, Effect of Ionic Liquid on Mechanical Properties and Morphology of Zwitterionic Copolymer Membranes, Macromolecules 43(2) (2010) 790-796.

[56] A. Laschewsky, I. Zerbe, Polymerizable and Polymeric Zwitterionic Surfactants .1. Synthesis and Bulk Properties, Polymer 32(11) (1991) 2070-2080.

[57] W.M. Elshemey, A.A. Elfiky, W.A. Gawad, Correlation to protein conformation of wideangle X-ray scatter parameters, The protein journal 29(8) (2010) 545-550.

[58] M. Galin, E. Marchal, A. Mathis, B. Meurer, Y.M. Soto, J. Galin, Poly (sulphopropylbetaines): 3. Bulk properties, Polymer 28(11) (1987) 1937-1944.

[59] T. Wu, F.L. Beyer, R.H. Brown, R.B. Moore, T.E. Long, Influence of zwitterions on thermomechanical properties and morphology of acrylic copolymers: Implications for electroactive applications, Macromolecules 44(20) (2011) 8056-8063.

[60] J.S. Pedersen, Analysis of small-angle scattering data from colloids and polymer solutions: modeling and least-squares fitting, Advances in colloid and interface science 70 (1997) 171-210. [61] M. Schmid, Properties of cast films made from different ratios of whey protein isolate, hydrolysed whey protein isolate and glycerol, Materials 6(8) (2013) 3254-3269.

[62] K. Shi, Y. Huang, H. Yu, T.-C. Lee, Q. Huang, Reducing the brittleness of zein films through chemical modification, Journal of agricultural and food chemistry 59(1) (2010) 56-61. [63] X. Mo, X. Sun, Plasticization of soy protein polymer by polyol-based plasticizers, Journal of the American Oil Chemists' Society 79(2) (2002) 197-202. 
[64] T.L. Sun, T. Kurokawa, S. Kuroda, A.B. Ihsan, T. Akasaki, K. Sato, M.A. Haque, T. Nakajima, J.P. Gong, Physical hydrogels composed of polyampholytes demonstrate high toughness and viscoelasticity, Nature materials 12(10) (2013) 932-937.

[65] S. Wu, Q. Guo, S. Peng, N. Hameed, M. Kraska, B. Stühn, Y.-W. Mai, Toughening epoxy thermosets with block ionomer complexes: a nanostructure-mechanical property correlation, Macromolecules 45(9) (2012) 3829-3840.

[66] B.K. Kim, S.Y. Lee, J.S. Lee, S.H. Baek, Y.J. Choi, J.O. Lee, M. Xu, Polyurethane ionomers having shape memory effects, Polymer 39(13) (1998) 2803-2808.

[67] J.C. van Hest, Biosynthetic-synthetic polymer conjugates, Journal of Macromolecular Science, Part C: Polymer Reviews 47(1) (2007) 63-92.

[68] M.A. Gauthier, H.-A. Klok, Peptide/protein-polymer conjugates: synthetic strategies and design concepts, Chemical Communications (23) (2008) 2591-2611.

[69] V. Hernandez- Izquierdo, J. Krochta, Thermoplastic processing of proteins for film formation - a review, Journal of food science 73(2) (2008) R30-R39. 


\section{Material properties of the cyanobacterial reserve}

\section{polymer multi-L-arginyl-poly-L-aspartate}

\section{(cyanophycin)}

Nikita A. Khlystov ${ }^{\hat{t}+}$, Wui Yarn Chan ${ }^{+}$,Aditya M. Kunjapur, Weichao Shi, Kristala L. J. Prather and Bradley D. Olsen ${ }^{*}$.

Department of Chemical Engineering, Massachusetts Institute of Technology, 77 Massachusetts Ave, Cambridge MA, 02139

Table of Contents Graphic
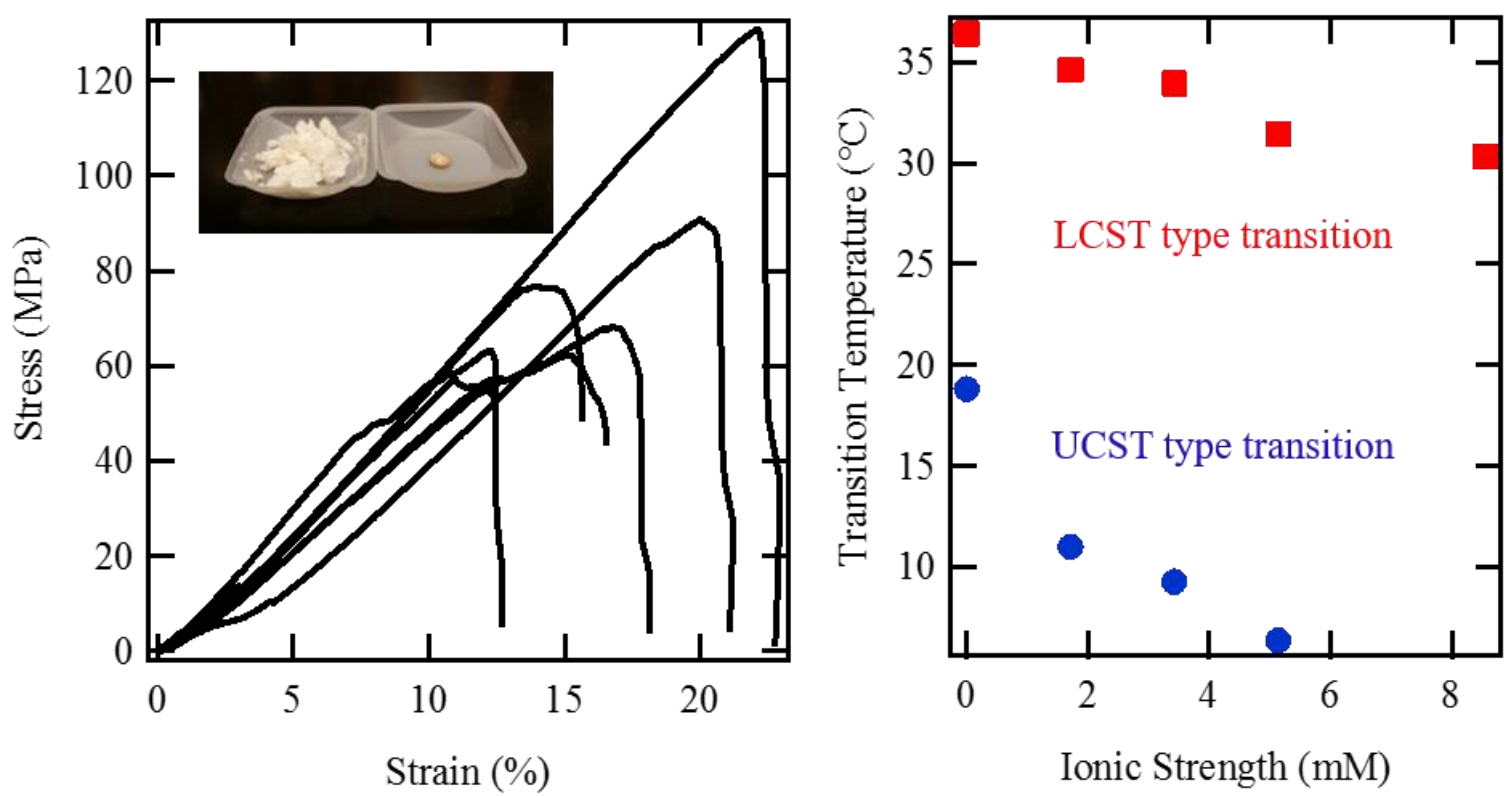